\title{
Single frequency intracavity SRO
}

\author{
Abitan, Haim; Buchhave, Preben
}

Published in:

Lasers and Electro-Optics Europe, 2000. Conference Digest

Link to article, DOI:

10.1109/CLEOE.2000.909683

Publication date:

2000

Document Version

Publisher's PDF, also known as Version of record

Link back to DTU Orbit

Citation (APA):

Abitan, H., \& Buchhave, P. (2000). Single frequency intracavity SRO. In Lasers and Electro-Optics Europe, 2000. Conference Digest IEEE. https://doi.org/10.1109/CLEOE.2000.909683

\section{General rights}

Copyright and moral rights for the publications made accessible in the public portal are retained by the authors and/or other copyright owners and it is a condition of accessing publications that users recognise and abide by the legal requirements associated with these rights.

- Users may download and print one copy of any publication from the public portal for the purpose of private study or research.

- You may not further distribute the material or use it for any profit-making activity or commercial gain

- You may freely distribute the URL identifying the publication in the public portal

If you believe that this document breaches copyright please contact us providing details, and we will remove access to the work immediately and investigate your claim. 


\section{Single Frequency Intracavity SRO}

\section{H. Abitan and P. Buchhave}

The Optics Group, Department of physics, The Technical University of Denmark

$$
\text { DK-2800 Lyngby, Denmark }
$$

E-mail: abitan fysik.dtu.dk 45-45253306

\section{Summery}

A single resonance optical parametric oscillator (SRO) is inserted intracavity to a $\mathrm{CW}$ high power, single frequency, and ring Nd:YVO4 laser. We obtain a stable single

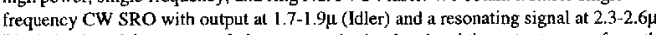
The behavior of the two coupled resonators is simulated and the output power from the SRO is described as a function of the diode pumping power supplied to the Nd:YVO4 SRO is

The diode pumped Nd:YvO4 laser is made unidirectional by the use of a ring configuration with a Faraday rotator and a half wave plate. The unidirectional operation configuration with a Furaday rolor and a hall wave pla cher the therefore one obteins a single frequency laser. The outpun power of such a laser is highly stable, duo to the steady single frequ . outpun power. Wo signal and idier generation. The SRO is operated when all the laser mirrors are highly signal and idier generation. Tib
reflective at $1064 n$ is in Fig :

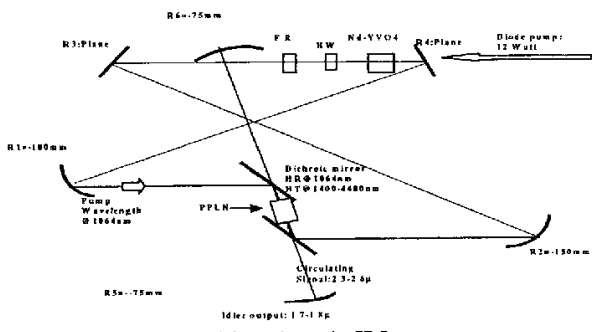

Fig.1: Two coupled cavities, A laser ring and a SRO.

\subsection{CMD6}

Methods for extending mode-hop-free tuning using a dual-cavity, pumpenhanced optical parametric oscillator

\section{McGloin, G.A. Turnball, I.D. Lindsay, M. Ebrahimzadeh \& M.H. Durn}

School of Physics \& Astronomy, University of St Andrews. Fife KY76 9SS, Scotland.

Tel.: +44 1334 463/85, Fax: 144133446310 e-mail:dm11@st-andac:uk

Continuous-wave (cw) optical paramertic ascillators (OPO's) are well suited to high-rcsolution speccroscopy applications e.g [e 8 1] Due to their low thresholds there has been imterest in using cw OPO's in which two

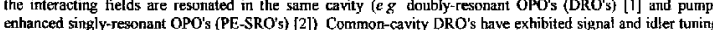
ranges equivalent to several cavity frec-spectral-ranges (FSR's), but PE-SRO's are limited by mode-hopping typically less than one FSR unless the phase-matching is tuned synctsronously with pump frequency Further, the idler turing range is limited in both cases to only a fiaction ( $v / v_{p}$ where $v_{i}$ and $v_{p}$ are the idfer and purn

We repor extended spectral tuning in PPLN based PE-SRO's Coarse wavelength uring from 27 to 53 um is possible and smooth single-frequency scanning ranges of over $10 \mathrm{GHz}$ are demonstrated The latter is accomplished by a novel dual-cavity configuration in which mode-hopping is suppressed We al so report a turthet vanant of the dual-cravity method in which the signal cavity is scanned synchronousty with the pump cavity 10 ' 'rack' the phase march bandwidth resulting in much larger tuning ranges chan in the

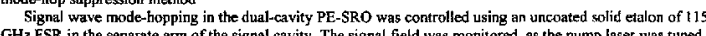
using a scanning confocal interfese signal cavity The signal field was monitored, as the pump laser was tured, frequency were observed using a Michelson interferometer of $18 G \mathrm{BZ}_{2}$ FSR Figure I shows the oulput of the Mishelson interferometer and corresponding change in enhancement cavity length ${ }_{\mathrm{p}}$ as the pump frequency was tuned repeatedly through $123 \mathrm{GHz}$ Within this range, we found that the idler frequency could be reliably tuned through $108 \mathrm{GHz}$ since no mode-hop wccurred in the signal field Enhancement of this tuning range using the synchronously tuned signal and pump field methixd will be discassed.

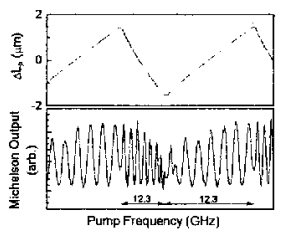

G M Gibson M J Padyet, M Ebratimzadeh and M/H Dunn, Opt. Letr. 24. 397 (1999) [2] G Roberison, M J Padgett and M H Dunn. Opt Leett (9, 1735 (1994) 